\title{
Persistence of Venturia inaequalis Populations Resistant to Strobilurins in the Field and in the Glasshouse
}

\author{
Riccardo Fiaccadori \\ Department of Agricultural Sciences (DIPSA), University of Bologna, Bologna, Italy \\ Email: riccardo.fiaccadori@unibo.it
}

How to cite this paper: Fiaccadori, R. (2018) Persistence of Venturia inaequalis Populations Resistant to Strobilurins in the Field and in the Glasshouse. American Journal of Plant Sciences, 9, 552-560. https://doi.org/10.4236/ajps.2018.94042

Received: November 18, 2017

Accepted: March 4, 2018

Published: March 7, 2018

Copyright $\odot 2018$ by author and Scientific Research Publishing Inc. This work is licensed under the Creative Commons Attribution International License (CC BY 4.0).

http://creativecommons.org/licenses/by/4.0/

\section{cc) (i) Open Access}

\begin{abstract}
The research was focused on the persistence of resistance of $V$. inaequalis to strobilurins from resistant populations occurring in the field. It was studied with two types of experiments: the first in apple orchards where resistance occurred in 2005 and employ of these fungicides was suspended from 2006 to 2011, realizing every year sensitivity/resistance assays on strobilurins. In the second was verified the sensitivity/resistance of the same 2015 populations, repeatedly multiplied (ten inoculations) in glasshouse on apple seedlings. Results showed that the resistance survived in orchards all the years of tests (six years), despite sensitivity fluctuations occurred on infected leaves due to sexual crosses, competition with sensible strains and soil management. In glasshouse, the level of resistance of all populations increased quickly in first inoculations and values remained high $\left(\mathrm{EC}_{50}>10 \mathrm{mg} \cdot \mathrm{L}^{-1}\right)$ in all the following inoculations, until the last, the 10th. $V$. inaequalis resistant strains seemed to show high fitness: relevant persistence in the field, and a capacity of prevail on sensible ones in absence of factors of field variability.
\end{abstract}

\section{Keywords}

Venturia inaequalis, Persistence, Resistance, Strobilurins, Scab Management

\section{Introduction}

Venturia inaequalis (Cke) Wint. is the causal agent of one of the most important diseases of apple cultivation in over 65 countries in the world [1]. The control of this disease requires many treatments with several chemical groups of fungicides and possibly an expert technical organization. Strobilurins fungicides, named also QoI (Inhibitors of Quinone outside), were introduced at the end of 90 years. 
They showed excellent activity against apple scab even when applied under high concentration of inoculum and favorable epidemiological conditions. However, cases of practical resistance of $V$. inaequalis were reported in the early 2000s [2] [3] and were confirmed by further surveys [4] [5].

In particular, the survey conducted in Italy showed that the presence and frequency of resistance to strobilurins differed among apple areas [6] and in those more interested by the problem the use of these QoI fungicides was generally interrupted. The knowledge of the fitness of these populations could be interesting in these situations, especially to evaluate the persistence and the possibility to the back employ of these fungicides where the problem occurred. There is currently a lack of information about the persistence of resistant populations to different fungicides groups: few reports deal on SBI and dicarboximides, while a higher number of researches are available for benzimidazoles. Concerning the last group of fungicides, resistant strains have shown a high persistence of resistance, 10 years in Tapesia sp. [7] and over 4 years in Venturia pirina [8]. A persistence of resistance of 10 years was also detected for ethirimol (chemical group IBS) in Spaeroteca fuliginea [9], while resistance to dicarboximides showed a rather high decrease after two years of no use on Botrytis cinerea [10] and Monilia fructicola [11].

The aim of this research was to verify the evolutions of $V$. inaequalis populations that were found to be resistant to strobilurins in Italian commercial orchards in 2005. Experiments were realized following two lines: 1) to verify the persistence of resistance of these 2005 field populations in the same orchards, from 2006 to 2011, in which strobilurins were no more used;2) to assay persistence of resistance and fitness of these 2005 resistant populations in glasshouse, in absence of perturbative agents on these phenotypes (gamic cross, climatic and epidemiologic situations, fungicides etc.).

\section{Materials and Methods}

\subsection{Population's Collection}

Populations of $V$. inaequalis were collected from four apple orchards (N. 143, 144, 148 and 150, comprehending apples cv Imperatore Dallago, from five to eight years old)of Emilia-Romagna Region (Northern Italy) where strobilurin fungicides (kresoxim-methyl firstly and trifloxystrobin subsequently) were applied for several years, and where resistance to strobilurins in 2005 was detected [3].

So scabbed leaves (30 - 50 in number) of the field for each population were randomly collected and 50 - 60 scab spots were added with a drop of sterile water, successively sucked, obtaining a dispersion with conidia. It was filtered and adjusted to a conidia concentration of $1-2 \times 10^{5} \mathrm{~mL}^{-1}$. The dispersion was inoculated on leaves of apple seedlings in glasshouse and after about 22 days the leaves with sporulated conidia were detached and conserved in silica gel until the use in the two kinds of test. 


\subsection{Persistence of Resistance: Assays in the Field}

In the tested orchards, where strobilurins were used and resistance was detected in 2005, strobilurins were not applied from 2006 to 2011, and apple scab control was carried out with other kind of fungicides such as aniline-pyrimidines, sterol biosynthesis inhibitors and dithianon.

Every year, samples of leaves were collected in each orchard, at the end of primary or at the beginning of secondary infective cycle, choosing scabbed leaves, on which was realized the multiplication of conidia, as explained before.

\subsubsection{Preparation of Fungicide}

The strobilurin named trifloxystrobin was used for tests, because it was the mostly employed in considered orchards and in apple areas. The fungicide was used as active material (Sigma-Aldrich, St. Louis, USA). It was dissolved in acetone at final concentration $<0.01 \mathrm{~L}^{-1}$ and added to water-agar (2\%, Agar Grade A, Becton, Dickinson and Company) to achieve the following fungicide concentrations: $0,0.001,0.01,0.1$ and $2 \mathrm{mg} \cdot \mathrm{L}^{-1}$. The antibiotic streptomycin sulphate was added to water agar at a final concentration of $200 \mathrm{mg} \cdot \mathrm{L}^{-1}$.

\subsubsection{Preparation of Conidia}

Pieces $(0.01 \mathrm{~g})$ of scabbed leaves were randomly collected from each multiplied population and introduced in micro tubes containing $1 \mathrm{~mL}$ of sterile water. After shaking, the conidial concentration was adjusted to $1-3 \times 10^{5}$ conidiam $\mathrm{L}^{-1}$. Two drops of $20 \mu \mathrm{L}$ of spore suspension for every fungicide concentration were placed on agar plates and incubated for 24 hours at $20^{\circ} \mathrm{C}$.

\subsubsection{In Vitro Assays}

300 conidia per concentration were visually assessed at the microscope, counting those germinated. Tests showing less than $50 \%$ conidia germinated in the control were not considered. On each population the assays were repeated three times, which permitted to get the mean (geometric) $\mathrm{EC}_{50}$ values (fungicide Efficacy Concentration reducing 50\% the percentage of germination of conidia) by probits analysis and $\mathrm{EC}_{50}$ max (maximum value of $\mathrm{EC}_{50}$ detected among the several in vitro tests on every population). $\mathrm{EC}_{50}$ values were calculated with probits using Finney \& Stevens table [12]. The software of the probits program was Excel.

The classification of a population as sensible or resistant was based on previous researches on different types of population (wild type, well and poorly controlled ones) that showed specific sensitivities [3] [6].

The used parameter was the $\mathrm{EC}_{50}$ max value because had a practical use, identifying the lowest value of sensitivity in population and consequently in the orchard. Sensible populations showed all the EC50 values inferior to $0.063 \mathrm{mg} / \mathrm{L}$. When at least one $\mathrm{EC}_{50}$ value was higher than $0.169 \mathrm{mg} \cdot \mathrm{L}^{-1}$, the population was considered resistant. Values in the very short intermediate range from 0.063 and $0.169 \mathrm{mg} / \mathrm{L}$ are considered in an intermediate situation, difficultly to evaluate as sensitivity. Wild-types populations showed always $\mathrm{EC}_{50}$ values inferior to 0.031 
$\mathrm{mg} / \mathrm{L}$.

A classification of populations was also realized as mean $\mathrm{EC}_{50}$ values, where wild-type populations have $\mathrm{EC}_{50}$ mean inferior to $0.013 \mathrm{mg} / \mathrm{L}$, those sensible are inferior to $0.049 \mathrm{mg} / \mathrm{L}$, while that resistant are superior to $0.049 \mathrm{mg} / \mathrm{L}$. This method presents values not highly different from that based on EC50 max, but this is more reliable for a practical evaluation of the presence of resistance in the orchards. However the $\mathrm{EC}_{50}$ value presents the advantage to be scientifically more available for evaluations of sensitivity of populations and can be better utilized in statistic elaborations.

\subsection{Persistence of Resistance: Assays in Glasshouse}

The conidia from orchards with resistance to strobilurins, after the propagation (see Chapter 2.2), were repeatedly inoculated on apple seedlings (10 times) in glasshouse, using always the conidia of the previous inoculation (Table 4). The inoculations were realized with little mechanical sprayers containing from 20 to $30 \mathrm{~mL}$. After two-four inoculations, the conidia of each sample were subjected to an in vitro evaluation on strobilurins sensitivity. Each inoculation was realized on 8 - 10 apple seedlings (cv. Golden), 4 - 5 weeks old, with 5 - 7 formed leaves.

Inoculation of $V$. inaequalis populations was performed with a suspension of conidia at the concentration of $1-2 \times 10^{5} \mathrm{~mL}$ of sterile water that was uniformly sprayed on both leaf surfaces ( $1.2 \mathrm{~mL}$ each plant). The seedlings were then put in a plastic bag, closed to maintain wetness on leaves for 48 hours at $18^{\circ} \mathrm{C}$. Subsequently the plants were incubated for further 18 days with light at an intensity of $25 \mu$ Einstein. $\mathrm{m}^{-2} \cdot \mathrm{s}^{-2}$, a photoperiod of 12 hours a day, mean temperature about $18^{\circ} \mathrm{C}$ and $60 \%-80 \%$ relative humidity. Then the scabbed leaves were collected and dried with paper and silica gel until the following inoculation.

\subsubsection{Sensitivity Assays In Vivo}

To evaluate the persistence of resistance, in vitro tests (sensitivity as $\mathrm{EC}_{50}$ values) were realized with the same methodology used for field and glasshouse populations. Three assays were realized, utilizing for each one a subpopulation with a part of scabbed leaves. The methodology used was previously described in the paper.

\subsubsection{Statistic Analysis}

ANOVA factorial analysis was preliminarily realized on the three populations with the higher number of data based on the most important parameter: mean $\mathrm{EC}_{50}$ value. Successively a non-parametric analysis with ez-Perm function (Ez package in R) was performed [Stat.Soft.inc. (2013), STATISTICA (version 12)], P: 0.05 .

\section{Results}

\subsection{Assays from Orchards}

The evolution of sensitivity to strobilurins from 2005 to 2011 in the four orc- 
hards, expressed as concentrations of fungicide (mean and max $\mathrm{EC}_{50}$ values) is showed in Table 1 and data are evaluated with parametric and non parametric analysis. $\mathrm{EC}_{50}$ values in the first year presented a rather high range of values. The populations N. 143 presented high mean and $\max \mathrm{EC}_{50}$ values in 2005, and showed a light fluctuation of sensitivity in the following years, without employ of strobilurins, always in the range of resistant values, returning in 2011 to $\mathrm{EC}_{50}$ values similar to 2005 .

Population N. 144 presented lower values (as $\mathrm{EC}_{50}$ ) in 2005, but in the following years, the $\mathrm{EC}_{50}$ 's showed no reduction, but on the contrary, there is an increase until 2011. Even in this case the $\mathrm{EC}_{50}$ values are always superior to the minimum values for resistance.

In addition, population N. 150 showed a variability of $\mathrm{EC}_{50}$ values (both considering mean and max), with fluctuations in the years, from 2005 to 2009, that, however, permitted to population to remain always in a situation of resistance.

Samples of population N. 148 were collected only in 2005, 2009 and 2011 and showed, quite always, very low values of sensitivity as $\mathrm{EC}_{50}$ values, with only a case in 2011, of moderate increase of sensitivity $\left(\mathrm{EC}_{50}\right.$ mean) that remained, however, in a situation of resistance.

The statistic elaboration used, with ANOVA factorial analysis (Table 2), showed no differences about mean sensitivity data among the populations and the years; but it presents a poor homogeneity in variance.

As data are not suitable to be examined in a parametric method, anon-parametric analysis with ez-Perm function was realized (Table 3). Also this elaboration evidenced a non significative interaction between years and populations in $\mathrm{EC}_{50}$ means; so all the sensitivity values, in all considered years, were caused only by the occurrence and the persistence of resistance.

Table 1. Effective $\mathrm{EC}_{50}$ values of trifloxystrobin on $V$. inaequalis resistant populations in commercial orchards from 2005 to 2011.

\begin{tabular}{|c|c|c|c|c|c|c|c|c|c|c|c|c|c|c|}
\hline \multirow{2}{*}{$\begin{array}{c}\mathrm{N}^{\circ} \\
\text { population }\end{array}$} & \multicolumn{2}{|c|}{2005} & \multicolumn{2}{|c|}{2006} & \multicolumn{2}{|c|}{2007} & \multicolumn{2}{|c|}{2008} & \multicolumn{2}{|c|}{2009} & \multicolumn{2}{|c|}{2010} & \multicolumn{2}{|c|}{2011} \\
\hline & $\begin{array}{l}\mathrm{EC}_{50} \\
\text { mean }\end{array}$ & $\begin{array}{l}\mathrm{EC}_{50} \\
\max \end{array}$ & $\begin{array}{l}\mathrm{EC}_{50} \\
\text { mean }\end{array}$ & $\begin{array}{l}\mathrm{EC}_{50} \\
\max \end{array}$ & $\begin{array}{l}\mathrm{EC}_{50} \\
\text { mean }\end{array}$ & $\begin{array}{l}\mathrm{EC}_{50} \\
\max \end{array}$ & $\begin{array}{l}\mathrm{EC}_{50} \\
\text { mean }\end{array}$ & $\begin{array}{l}\mathrm{EC}_{50} \\
\max \end{array}$ & $\begin{array}{l}\mathrm{EC}_{50} \\
\text { mean }\end{array}$ & $\begin{array}{l}\mathrm{EC}_{50} \\
\max \end{array}$ & $\begin{array}{l}\mathrm{EC}_{50} \\
\text { mean }\end{array}$ & $\begin{array}{l}\mathrm{EC}_{50} \\
\max \end{array}$ & $\begin{array}{l}\mathrm{EC}_{50} \\
\text { mean }\end{array}$ & $\begin{array}{l}\mathrm{EC}_{50} \\
\max \end{array}$ \\
\hline 143 & $>10$ & $>10$ & 3.3 & 5.6 & 2.11 & 4.60 & 1.81 & $>10$ & 7.35 & $>10$ & 1 & 1 & 3.7 & $>10$ \\
\hline 144 & 0.32 & 4.11 & 0.29 & 3.19 & 1.47 & 1.92 & 1.2 & 6.6 & 3.68 & $>10$ & $>10$ & $>10$ & 7.6 & $<10$ \\
\hline 150 & 1.11 & 6.47 & $>10$ & $>10$ & 1.25 & 5.12 & 2.11 & 4.8 & 3.42 & $<10$ & & 2 & & \\
\hline 148 & $>10$ & $>10$ & 1 & 1 & 1 & 1 & 1 & 1 & $>10$ & $>10$ & 1 & 1 & 1.48 & $>10$ \\
\hline
\end{tabular}

1: sample not available; 2 : estirpate orchard.

Table 2. Parametric variance analysis with ANOVA test.

\begin{tabular}{cccccc}
\hline Effect & Sum of squares & Degree of freedom & Variance & Variance error & F-value \\
Year & 132.72 & 5 & 26.45 & 29.98 & 0.88 \\
Population & 4.25 & 2 & 2.12 & 29.98 & 0.07 \\
Year $\times$ population & 269.90 & 9 & 29.98 & 27.95 & 0.93 \\
\hline
\end{tabular}


Table 3. Non-parametric analysis of variance with EZ-Perm.

\begin{tabular}{|c|c|c|c|c|c|c|c|c|}
\hline \multirow{2}{*}{ Effect } & \multirow{2}{*}{$\begin{array}{l}\text { Effect } \\
(\mathrm{F} / \mathrm{R})\end{array}$} & \multirow{2}{*}{ SS } & \multirow{2}{*}{$\begin{array}{c}\text { Degree } \\
\text { Freedom }\end{array}$} & \multirow{2}{*}{ MS } & \multirow{2}{*}{$\begin{array}{c}\text { Den.Syn. } \\
\text { Error df }\end{array}$} & \multirow{2}{*}{$\begin{array}{c}\text { Den.Syn. } \\
\text { Error MS }\end{array}$} & \multirow{2}{*}{ F-value } & \multirow{2}{*}{ P-value } \\
\hline & & & & & & & & \\
\hline Intercept & Fixed & 183.38 & 1 & 183.38 & 5.04 & 26.46 & 6.92 & 0.04 \\
\hline Year & Random & 132.27 & 5 & 26.45 & 9.00 & 29.98 & 0.88 & 0.53 \\
\hline Popul/site & Fixed & 4.25 & 2 & 2.12 & 9.00 & 29.98 & 0.07 & 0.93 \\
\hline Year $\times$ popul $/$ site & Random & 269.90 & 9 & 29.98 & 34.00 & 27.95 & 1.07 & 0.40 \\
\hline Error & & 950.32 & 34 & 27.95 & & & & \\
\hline
\end{tabular}

\subsection{Assays from Glasshouse}

Three of the four $V$. inaequalis populations, which occurred as resistant to strobilurins in orchards in 2005 year, were used also for glasshouse studies. These populations were repeatedly inoculated in glasshouse as reported in Table 4. The first examined population, N. 143, showed very high $\mathrm{EC}_{50}$ values in the first assessment (after the second inoculation), similar to that of field sensitivity in 2005. This high reduction of sensitivity (mean and max $\mathrm{EC}_{50}$ values) remained constantly high also after the $4^{\text {th }}, 8^{\text {th }}$ and $10^{\text {th }}$ inoculation.

Also the population N. 144 showed very high $\mathrm{EC}_{50}$ values already after the first assessment ( $2^{\text {nd }}$ inoculation) with mean and $\max \mathrm{EC}_{50}$ values that are sensibly higher compared to the initial sensitivity in 2005. This population maintained substantially the same level of very low sensitivity after the other three inoculations.

Likewise the population N. 150 presented a very low sensitivity already after the first glasshouse assessment, showing higher $\mathrm{EC}_{50}$ (mean and max) compared to the initial sensitivity values from the orchard. The population maintains the same high degree of resistance also after the three cited assays, subsequent to the $4^{\text {th }}, 8^{\text {th }}$ and $10^{\text {th }}$ inoculation.

\section{Discussion}

The research was carried out examining $V$. inaequalis populations from four Italian orchards that were assayed and classified as resistant to strobilurins in 2005 (characterized by poor field control and high $\mathrm{EC}_{50}$ values for the prevalence of resistant spores respecting sensible ones). The evolution and persistence of resistant populations were studied in that orchards, assaying sensitivity to strobilurins in the following six years), and in glasshouse, where the populations coming from these orchards were repeatedly inoculated (ten times).

The assessment of sensitivity of $V$. inaequalis populations permits to evidence that all tested orchards can be considered resistant during all the six years, despite fluctuations in sensitivity due to several causes.

Indeed all fungi populations, comprehending also those that are a mix between sensible and resistant spores, present sexual crosses between antheridia and oogonia in parasitic phase of the fungus in winter that can modify characteristics of strains and populations, also regarding sensitivity. Moreover, during 
Table 4. Mean $\mathrm{EC}_{50}$ values of trifloxystrobin on $V$. inaequalis resistant populations, repeatedly inoculated ${ }^{\star}$ on seedlings in glasshouse.

\begin{tabular}{|c|c|c|c|c|c|c|c|c|c|c|}
\hline \multirow{3}{*}{ 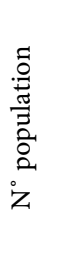 } & \multirow{2}{*}{\multicolumn{2}{|c|}{$\begin{array}{c}\text { Initial } \\
\text { sensitivity of } \\
\text { populations } \\
(2005)\end{array}$}} & \multicolumn{8}{|c|}{ Results of sensitivity (in vitro test) on spores after the sporulation of: } \\
\hline & & & \multicolumn{2}{|c|}{$\begin{array}{c}2^{\text {nd }} \\
\text { inoculation }\end{array}$} & \multicolumn{2}{|c|}{$4^{\text {th }}$ inoculation } & \multicolumn{2}{|c|}{$8^{\text {th }}$ inoculation } & \multicolumn{2}{|c|}{$\begin{array}{l}10^{\text {th }} \\
\text { inoculation }\end{array}$} \\
\hline & $\begin{array}{c}\text { Mean } \\
\mathrm{EC}_{50}\end{array}$ & $\begin{array}{l}\text { Max } \\
\mathrm{EC}_{50}\end{array}$ & $\begin{array}{c}\text { Mean } \\
\mathrm{EC}_{50}\end{array}$ & $\begin{array}{l}\mathrm{Max} \\
\mathrm{EC}_{50}\end{array}$ & $\begin{array}{l}\text { Mean } \\
\mathrm{EC}_{50}\end{array}$ & $\begin{array}{l}\operatorname{Max} \\
\mathrm{EC}_{50}\end{array}$ & $\begin{array}{c}\text { Mean } \\
\mathrm{EC}_{50}\end{array}$ & $\begin{array}{l}\mathrm{Max} \\
\mathrm{EC}_{50}\end{array}$ & $\begin{array}{c}\text { Mean } \\
\mathrm{EC}_{50}\end{array}$ & $\begin{array}{l}\mathrm{Max} \\
\mathrm{EC}_{50}\end{array}$ \\
\hline 143 & $>10$ & $>10$ & 8.6 & $>10$ & $>10$ & $>10$ & $>10$ & $>10$ & $>10$ & $>10$ \\
\hline 144 & 0.32 & 0.39 & $>10$ & $>10$ & $>10$ & $>10$ & $>10$ & $>10$ & $>10$ & $>10$ \\
\hline 150 & 0.18 & 6.47 & $>10$ & $>10$ & $>10$ & $>10$ & $>10$ & $>10$ & $>10$ & $>10$ \\
\hline
\end{tabular}

${ }^{*}$ Inoculations: $1^{\text {st }} 08.05 .09 ; 2^{\text {nd }} 10.11 .09 ; 3^{\text {rd }} 29.12 .09 ; 4^{\text {th }} 02.02 .10 ; 5^{\text {th }} 31.03 .10 ; 6^{\text {th }} 12.05 .10 ; 7^{\text {th }} 17.06 .10 ; 8^{\text {th }}$ $12.07 .10 ; 9^{\text {th }} 07.09 .11 ; 10^{\text {th }} 08.01 .11$.

the vegetative phase, the competition between resistant and sensible strains during repeated agamic cycles of the fungus can modify the proportion of resistant and sensible spores. In addition, the soil management could have influence, as lawn permits a better conservation of the leaves and of the populations of $V$. inaequalis, while ploughings and shredding could cause reductions, selections and modifications of populations. However, I have observed that these modifications were not able to modify the status of populations which have a majority of spores resistant to strobilurins. Concluding, the presented data emphasize that the resistance of $V$. inaequalis to strobilurins showed characteristics of a long persistence in the orchards, at least 6 years.

The assays in glasshouse evidenced that repeated inocula increased quickly the levels of resistance until the maximum admissible values $\left(\mathrm{EC}_{50}>10 \mathrm{mg} / \mathrm{L}\right)$. It must be pointed out that the conidia were used in glasshouse, only with agamic multiplications, while the conservation occurred at $-20^{\circ} \mathrm{C}$, in lyophilized status. In these situations, these conidia appear to undergo an inferior variability respecting those in field conditions, previously examined.

As presented in introduction, the knowledges about the persistence of fungicide resistance of strains of populations are very low on less recent chemical groups (IBS, dicarbossimides, benzimidazoles) and practically absent on more recent others, as strobilurins, and anilino-pyrimidines. Now we are continuing researches on persistence to QoI in the same orchards and are working on persistence of resistance to difenoconazole, but I do not know other research groups that are involved on the same arguments.

The persistence of resistance in fungi populations is an aspect of the much wider argument of the fitness of resistance strains.

About strains resistant to strobilirins, researches on Erisiphe graminis showed no differences in aggressiveness between the two types of strains (sensible and resistant) [13], while in several other cases a reduced fitness of isolates resistant to strobilurins is reported, but it must be pointed out that it generally concerns artificial mutants with the introduction of G143A substitution, as on Botrytis cinerea [14]. However it is not known the field behavior of these resistant 
strains.

\section{Conclusions}

In conclusion, the aspects of fitness studied that spores resistant to strobilurins, generally related to G143A substitution, do not present a lower fitness respecting sensible ones, as demonstrated on animal and vegetal types of organisms [15]. Our research on Venturia inaequalis, especially in glasshouse, supports the theory that the resistant strains to strobilurins present characteristics of fitness surely not inferior to that of sensible strains. I also demonstrated the maintenance of resistance in orchards for several years after its appearance.

Moreover, in controlled conditions, where genetic, environmental or agronomic factors cannot influence these phenotypes and genotypes, the fitness of strains resistant to strobilurins seemed to appear superior to that of sensible strains. However very few data are available about fitness of other resistant fungi populations respecting sensible ones, with referring to all recent and actually used fungicides.

\section{Acknowledgements}

Thanks to Enrico Muzzi for advising in statistic analysis, Angela Finestrelli and Elena Cicognani for laboratory help, A. Gilli for field supervision, Cesare Gessler for advices and Marina Collina for logistic help.

\section{Fund}

Research realized with fund by Regione Emilia-Romagna (Italy) Servizio Fitosanitario Regionale.

\section{References}

[1] MacHardy, W.E. (1996) Apple Scab Biology, Epidemiology and Management. APS Press, St. Paul, Minnesota, 3.

[2] Kuck, K.H. and Mehl, A. (2003) Trifloxystrobin: Resistance Risk and Resistance Management. Pflanzenschutz Nachrichten Bayer, 56, 313-325.

[3] Fiaccadori, R., Cicognani, E., Abbatecola, M., Collina, M. and Brunelli, A. (2005) Sensitivity of Venturia inaequalis to Strobilurin Fungicides in Italy. Communications in Agricultural and Applied Biological Sciences, 70, 73-78.

[4] Sallato, B.V., Latorre, B.A. and Aylwin, G. (2006) First Report on Practical Resistance to QoI Fungicides in Venturia inaequalis (Apple Scab) in Chile. Plant Disease, 90, 375. https://doi.org/10.1094/PD-90-0375A

[5] Lesniak, K., Proffer, T., Beckerman, J. and Sundin, G. (2011) Occurrence of QoI Resistance and Detection of the G143A Mutation in Michigan Populations of Venturia inaequalis. Plant Disease, 95, 927-934. https://doi.org/10.1094/PDIS-12-10-0898

[6] Fiaccadori, R., Collina, M. and Brunelli, A. (2013) Reduced Sensitivity of Venturia inaequalis to Strobilurins and Anilinopyrimidines in Italy. Proceedings " 8 th International Conference on Integrated Fruit Production”, IOBC-WPRS Bulletin, 91, 345-350.

[7] Leroux, M. and Gredt, E. (1997) Evolution of Fungicide Resistance in the Cereal 
Eyespot Fungi, Tapesia yallundae and Tapesiaacuformisin France. Pesticide Science, 51, 312 .

https://doi.org/10.1002/(SICI)1096-9063(199711)51:3<321::AID-PS639>3.0.CO;2-U

[8] Shabi, E. and Kaian, I. (1980) Fitness of Venturiapirina Isolates Resistant to Benzimidazoles Fungicides. Phytopathology, 70, 1172-1174.

https://doi.org/10.1094/Phyto-70-1172

[9] Schepers, H.T.A.M. (1984) Persistence of Resistance to Fungicides in Sphaeroteca fuliginea. Netherlands Journal of Plant Pathology, 90, 165-171. https://doi.org/10.1007/BF02006480

[10] Northover, J. (1988) Persistence of Dicarboximide-Resistant Botrytis cinerea in Ontario vineyards. Canadian Journal of Plant Pathology, 10, 123-132.

https://doi.org/10.1080/07060668809501744

[11] Sanomuang, N. and Gaunt, R.E. (1995) Persistence and Fitness of Carbendazimand Dicarboximide-Resistant Isolates of Monilia fructicola (Wint.) Honey in Flowers, Shoots and Fruits of Stone Fruits. Plant Pathology, 44, 448-457. https://doi.org/10.1111/j.1365-3059.1995.tb01667.x

[12] Finney, D.J. and Stevens, W.L. (1948) A Table for the Calculation of Working Probits and Weights in Probit Analysis. Biometrika, 35, 191-201. https://doi.org/10.1093/biomet/35.1-2.191

[13] Chin, K.M., Chavaillaz, D., Kaebuhrer, M., Staub, T. and Felsenstein, F.G. (2001) Characterizing Resistance Risk of Erisiphegraminisf. sp. tritici to Strobilurins. Crop Protection, 20, 87-96. https://doi.org/10.1016/S0261-2194(00)00059-4

[14] Markoglou, A.N., Malandrakis, A.A., Vitoratos, A.G. and Ziogas, B.N. (2006) Characterization of Laboratory Mutants of Botrytis cinerea Resistant to QoI Fungicides. European Journal of Plant Pathology, 115, 149-162. https://doi.org/10.1007/s10658-006-0008-2

[15] Brasseur, G., Saribas, S.A. and Daldal, F. (1996) A Compilation of Mutations Located in the Cytochrome bsubunit of the Bacterial and Mitochondrial $b c_{1}$ Complex. Biochimicaet Biophysica Acta, 1275, 61-69.

https://doi.org/10.1016/0005-2728(96)00051-5 